\title{
RECENTES AVANÇOS EM ERROS INATOS DO METABOLISMO
}

\author{
$A R O N J, D I A M E N T *$
}

Nāo é fácil discorrer sobre recentes avanços em erros inatos do metabolismo (EIM) se considerarmos o que se passa na literatura a respeito desse tópico, pois há inúmeras publicaçóes sobre: novos erros descobertos, variantes dos já descritos, a comprensăo mais real de determinadas cadeias metabólicas que estavam mal esclarecidas, a descoberta de novas cadeias alternativas com metabólitos diferentes, entre outras. Tentaremos enfocar o assunto por 4 aspectos relacionados aos avanços: 1. na compreensão geral dos EIM; 2. nos aspectos clínicos; 3. nos aspectos diagnósticos, abrangendo o diagnóstico pré-natal; 4. nos aspectos terapêuticos.

\section{ASPECTOS GERAIS}

Atualmente, mais de 3000 desordens congènitas, a maioria de origem hereditária, foram catalogadas e identificadas segundo McKusick 16. Dessas, pouco mais de duzentas são conseqüência de aberrações cromossômicas 21 e algumas centenas são devidas à combinação de fatores ambientais e poligênicos. Restam cerca de 2800 condições cuja causa varia desde modificaçōes proteicas dificilmente detectáveis, que constituem a maioria, até doenças metabólicas progressivas e fatais e que são reconhecidas como devidas a mutação gênica única 16 . Os fatores que complicam o reconhecimento da maioria dessas entidades são: o grande numero de desordens congênitas diferentes, sua relativa baixa incidência e a heterogenidade clínica, bioquimica e genética entre essas diferentes desordens e, freqüentemente, num mesmo tipo de desordem e/ou doença. Entretanto, os avanços tecnológicos dos últimos 40 anos vieram esclarecer várias dessas etiologias e reconhecer certo numero de entidades até então conhecido pelos estudos de frequência populacional e heredogramas.

Desde a descrição do número exato de cromossomos da espécie humana em 1956 por Tijo \& Levan (in Diament 7 ) e, em 1959, da descrição da primeira aberração cromossômica por Lejeune \& col. (in Diament 7), muito progrediu a genética auxiliada pela bioquímica e pela biologia molecular. Além das técnicas que permitiram o reconhecimento do numero de cromossomos, passou-se também ao reconhecimento da estrutura desses elementos celulares pelo estudo das bandas cromossômicas, criando-se uma verdadeira anatomia cromossômica 16. A par dessa evolução dos estudos cromossômicos, a genética sofreu enorme avanço após a descoberta da estrutura do DNA e do código genético no inicio da década de 60 . Desenvolveu-se então, verdadeira revolução nesses conhecintentos que progrediram até os conceitos de genética molecular e/ou bioquimica genética e de engenharia genética. Isto foi possivel em vista do concomitante progresso na metodologia bioquimica 6 , a saber: métodos cromatográficos nas suas várias modalidades, radioensaios, radio-imuno-ensaios, imu-

* Professor Adjunto do Departamento de Neurologia da Faculdade de Medicina da Universidade de São Paulo (FMUSP), Chefe do Serviço de Neurologia Infantil do Hospital das Clínicas da FMUSP. 
no-enzima-ensaios, métodos espectrofluorométricos mais acurados, utilização da luminiscência e do laser, métodos estes que permitiram determinaçōes de metabólitos de cadeias metabólicas bloqueadas e dosagem específica de enzimas e/ou proteinas envolvidas nos erros metabólicos. Daí o surgimento do conceito de marcadores genéticos que permitiram reconhecer o efeito do erro gênico conduzindo ao EIM. Por outro lado, técnicas envolvendo endonucleases, sonda de DNA e hibridização de DNA permtitiram o reconhecimento da localização gênica - os loci — em vírus e bactérias e, também, no homem. Para se ter idéia da complexidade desses estudos, devemos mencionar que os 46 cromossomos humanos contêm suficiente DNA para cerca de 3 a $5 \times 10^{9}$ nucleotideos; porém, o número total de pares gênicos ou loci foi estimado em 50000 (O'Brien, 1973; in Diament 7); se se levar em conta que uma proteina média de 350 aminoácidos (AMAC) requer $10^{3}$ nucleotideos, torna-se claro que o número de mutações gênicas pode ser enorme. Este fato se torna ainda mais patente se analisarmos o aumento progressivo do número de loci identificados pelas entradas sucessivas nas diversas ediçōes do catálogo de doenças transmissiveis mendelianas, editado pela Universidade Johns Hopkins 16, comparando-as a edição 1958 de um tratado de genética humana editado na Alemanha. Sendo conhecidas cerca de 2800 condiçōes genéticas devidas a mutação gênica única e, na verdade, só conhecemos o marcador genético, isto é, alguma dosagem enzimática e/ou proteica que permita seu reconhecimento em menos de $10 \%$ delas, e, dessas, nem todas tem seu locus identificado nos cromossomos 13,21,28. Supoem os geneticistas que cada um de nós é portador, ao menos, de 30 alelos raros que determinam muito de nossa individualidade bioquímica e que cerca de $75 \%$ das mutações gênicas são alterações básicas que determinam alterações do código genético de tal maneira que um AMAC diferente é inserido na cadeia polipeptídica 13,28. Se um polipeptideo médio contém cerca de 350 AMAC e uma proteína consiste de diversas cadeias polipeptidicas, o número de moléculas estruturalmente diferentes que pode ser produzido torna-se considerável. Estes fatos explicam a dificuldade em se determinar e/ou dosar os marcadores genéticos. Porém, mesmo assim, na última edição do referido catálogo 16, cerca de 350 genes já são de localizaçāo definida 21.

$\mathrm{Na}$ grande maioria das doenças genéticas é muito difícil, porém, detectar suas mutaçōes, o que é mais evidente no caso das doenças dominantes, nas quais dificilmente encontramos um marcador genético. Mais ainda, o que se verificou nas duas últimas décadas é que muitos EIM apresentam considerável heterogeneidade clínica e bioquimica. Podemos citar vários exemplos $13: 1^{\circ}$ ) 0 tipo infantil clássico da glicogenose tipo Il (ou moléstia de Pompe), com severas manifestaçōes clínicas logo após o nascimento, conduz à morte aos 2-4 anos de idade por falência cardíaca, enquanto os do tipo adulto só apresentam queixas de fraqueza muscular; porém, o cultivo de leucócitos ou fibroblastos ou de células hepáticas mostrou, em ambos, a deficiência da enzima lisossômica alfa-1,4-glicosidase; $2^{\circ}$ ) deficiência da enzima hipoxantina-guanina-fosforibosiltransferase (UGFT), cujo déficit completo causa a sindrome de Lesch-Nyhan, enquanto seu déficit parcial causa apenas artrite gotosa; $3^{\circ}$ ) deficiência da arisulfatase-A, cujo déficit completo causa a leucodistrofia metacromática, enquanto seu déficit parcial causa uma esclerose difusa disseminada $19 ; 4^{\circ}$ ) outra variante descrita é a relacionada ao déficit parcial da hexosaminidase-A no adulto levando a quadro diferente daquele descrito na moléstia de Tay-Sachs 1. O estudo das mutações gênicas, intensamente desenvolvido pelas técricas de hibridização de células somáticas, permitiu identificar e classificar variantes, além de corrigir eventuais erros enzimáticos. Durante a hibridização, por um processo chamado de complementação, estudou-se a beta-galactosidase após fusão de fibroblastos de pacientes com os tipos infantil clássico e juvenil da $\mathrm{GM}_{1}$-gangliosidose, com galactosidase de células deficitárias da variante adulta, tendo-se obtido a restauração da atividade enzimática; após alguns anos verificou-se que as células da variante adulta e de outros pacientes do mesmo grupo de complementação apresentavam déficit de neuraminidase; agora se sabe que a deficiência de beta-galactosidase é um efeito secundário 13. Outro estudo semelhante foi o 
efetuädo por fusão de fibroblastos de pacientes com moléstia de Tay-Sachs e de Sandhoff, verificando-se duas diferentes mutaçōes gênicas envolvidas e, a análise molecular efetuada (Beutler \& col., 1975, in Galjaard 13) revelou que as mutaçōes estavam localizadas em duas diferentes cadeias da hexosaminidase ácida.

\section{ASPECTOS CLANICOS}

Os aspectos clínicos dos avanços em EIM se caracterizam por duas ordens de fenômenos: a descrição de variantes de ElM já descritos e a descrição de novos EIM.

EIM DOS AMINOÁCIDOS (AMAC) - Quanto à descrição de variantes é já classicamente conhecido o relato das diversas causas de Hiperfenilalaninemias, a partir dos estudos de seleção populacional 30 . O simples bloqueio do fator lábil da fenilalanina-hidroxilase não era tão simples como foi descrito no início; descobriram-se erros na metabolização das pteridinas envolvidas na transformação de FAL em tirosina (TYR), além de defeito na transaminação da FAL.

No metabolismo da Tirosina (TYR), além das duas clássicas hipertirosinemias, descreveu-se recentemente o déficit da oxidase do ácido 4-hidroxifenilpirúvico, sem deficiência fumarilacetoacetase, numa criança do sexo masculino com 29 dias de idade 10; teve gestação e parto normais, pesando $4050 \mathrm{~g}$ ao nascimento; aos 21 dias de idade apresentou pneumonia e convulsóes $\mathrm{e}$, aos 29 dias, sua TYR era de $21 \mathrm{mg} / \mathrm{dl}$; melhorou com vitamina C (500 $\mathrm{mg} / \mathrm{dia})$ e com 46 dias apresentava fígado palpável, e crises tipo espasmo infantil, além de semi-coma; o EEG mostrava-se do tipo supressão e espículas ou polispículas nas áreas occipitais e parietal esquerda e a TAC mostrava atrofia cortical leve; o paciente excretava na urina grande quantidade de ácido 4-hidroxifenilpirúvico, além dos derivados acético e láctico do mesmo ácido; a atividade de oxidase do ácido 4-hidroxifenilpirúvico no fígado do paciente era $5 \%$ da normal.

No metabolismo da Leucina, descreveu-se a acidúria 3-metilglutacônica 8 em dois irmāos, com 7 e 5 anos de idade, ambos do sexo masculina e de origem marroquina; a única manifestação era retardo na aquisição da fala, não tendo ficado claro se apresentavam ou não leve DM. Excretavam na urina grandes quantidades de metabólicos da leucina: ácido 3-metil-glutacônico, ácido 3-metilglutárico e ácido-3-hidroxivalérico. Haveria um déficit parcial na enzima 3-metilglutaconil-CoA-hidratase.

No metabolismo da Valina se descreveu à deficiência de beta-hidroxi-isobutiril-CoA-deacilase 4 numa criança do sexo masculino de pais egípcios; é um dos raros exemplos de EIM nascido com malformações múltiplas, com dismorfismo facial, alimentação pobre, retardo no desenvolvimento neuropsicomotor, marcada hipotonia, anomalias vertebrais, tetralogia de Fallot e que faleceu aos três meses de idade; a necropsia confirmou a cardiopatia e mostrou agenesia do corpo caloso e do giro cíngulo.

Outro EIM de AMAC de cadeia ramificada é a deficiência de 3-hidroxi-3-metilglutaril-CoA-liase, descrita em 1976 por Faull \& col. (Tanaka \& col.29), e atualmente, com mais 4 pacientes; nascem normais e com a alimentação láctea apresentam nos primeiros dias episódios de vômitos, cianose, hipotonia, letargia e acidose metabólica; dois pacientes morreram durante esses episódios, dois se recuperaram e tiveram desenvolvimento normal após dieta restrita em proteinas e somente uma criança sofreu graves lesōes cerebrais durante um episódio, levando-a a hemiplegia e movimentos córeo-atetósicos.

A deficiência de 3-cetoliase envolve condição que interfere no catabolismo $\mathrm{da}$ isoleucina, levando à formação de propionil-CoA 29 . Produz episódios de acidose metabólica, vômitos, convulsões e febre, podendo levar a retardo mental 
por sucessivos episódios de acidose metabólica e convulsões; uma criança morreu num desses episódios.

No metabolismo do propionato, metilmalonato e cobalamina 20 , se descreveu a deficiência de carboxilases múltiplas, os pacientes apresentando crises de acidose metabólica que responderam bem à administração de biotina. Pode haver alopécia, crises convulsivas, hipotonia, odor anormal na urina (urina de gato) e defeito imunitário mas nāo em todos os casos. Haveria déficit de três enzimas biotino-dependentes: propionil-CoA-carboxilase; beta-metil-crotonil-CoA carboxilase e piruvato-carboxilase.

Ainda no metabolismo dos AMAC de cadeia ramificada, da lisina e dos ácidos graxos de cadeia longa descreveram-se: as acidúrias glutáricas tipos I e II e a acidúria etilmalônica-adipica 17. Caracterizam-se por apresentar hipoglicemia e crises de acidose metabólica, tendo convulsóes e episódios de vômitos; enquanto na acidúria glutárica tipo ll a hipoglicemia e as convulsões são severas, levando à morte, na acidúria etilmalônica-adípica, tal pode năo acontecer; a diferença entre essas duas entidades está ao nível da excreção dos metabólitos urinários, sendo o quadro clínico semelhante. A deficiência nas três entidades envolveria várias vias metabólicas incluindo AMAC de cadeia ramificada, ácidos graxos, lisina, hidroxilisina e triptofano; haveria bloqueio no degrau da enzima acil-CoA-desidrogenase.

No estudo do metabolismo do ácido gama-aminobutirico (GABA) descreveram-se nos últimos 5 anos, três novos EIM: 1) deficiência de succínico-semialdeido-desidrogenase 14, descrita por Jakobs \& col. em 1981 num paciente com $\mathrm{DM}$, ataxia $\mathrm{e}$ hipotonia muscular; os mesmos autores descreveram mais dois irmãos do primeiro paciente com idêntica anormalidade, apresentando $D M$, ataxia, problemas de comportamento e alterações oculares lembrando a ataxia telangiectasia; nos três pacientes, Gibson \& col.14 descreveram deficiência da enzima antes citada nos linfócitos: 2) deficiência da transaminase do ácido gama-aminobutirico: descrita no catabolismo do GABA por Rasting \& col., em 1982 (in Jaeken \& col.15) em dois irmãos apresentando associação incomum de doença cerebral severa com leucodistrofia e aceleração do crescimento; Jaeken \& col.15 descreveram dois outros pacientes irmãos (de sexos diferentes) e que apresentavam, logo após o nascimento, dificuldade alimentar, hipotonia, hiperreflexia generalizada (que depois desaparecia), grito agudo e freqüentes convulsões parciálmente controladas com fenobarbital e difenilhidantina, além de extremo retardo no desenvolvimento neuropsicomotor, aceleração no crescimento físico; a necrópsia do irmão revelou leucodistrofia; 3)deficiência de carboxilase do ácido glutâmico, descrita por Yoshida \& col.35, numa criança que apresentou convulsões vitamina B6-dependente; verificou-se o déficit da enzima por biópsia renal.

A transformaçāo por que passou o conceito de homocistinúria, permite constatar a diversidade de causas desta entidade, estreitamente ligada ao metabolismo da metionina e da citationina, verificando-se inclusive causas năo propriamente genético-metabólicas das três entidades (hipermetioninemia, homocistinúria, cistationinúria) 18 .

Dentre as Hiperornitinemias ressalta em importância a atrofia girata da coróide e retina (AGCR), moléstia autossômica recessiva, descrita bioquímicamente em 91 casos até 1983, metade đos quais de origem finlandesa 31 . Suas características clínicas săo: degeneração coriorretiniana progressiva, com miopatia, cegueira noturna e perda da visão periférica (as quais podem se iniciar na primeira década), seguindo-se visão tubular e até cegueira eventual nas segunda e terceira décadas; a seguir, pode surgir catarata subcapsular. Os músculos esqueléticos podem mostrar agregados tubulares nas fibras tipo II. A ornitina plasmática está elevada $(400 \mathrm{a} 1400 \mu \mathrm{m})$, assim como sua excreção urinária $(0,5$ a $10 \mathrm{mmol} /$ dia). Está diminuída a atividade da enzima ornitina-delta-aminotransferase em células e tecidos. Os pacientes respondem bem ao tratamento com 
piridoxal-fosfato ou piridoxina e dieta restrita em arginina ajuda a normalizar os níveis plasmáticos de ornitina, porém sem regressão das anormalidades visuais. A administração de creatinina ajudou a melhorar as anormalidades histológicas musculares.

EIM dos carboidratos - As acidoses lácticas passaram a ser melhor estudadas c entendidas quando várias delas foram enquadradas nos EIM do piruvato 2 : 1) Deficiência do complexo piruvato-desidrogenase (CPH)-relatada em cerca de 50 pacientes com 2 tipos clínicos: a) acidose láctica que cursa com retardo no desenvolvimento neuropsicomotor, apresentando microcefalia, atrofia óptica, hipotonia muscular e coordenação pobre, dando-se o óbito entre 5 e 6 anos de idade; a atividade da $\mathrm{CPH}$ varia de 7 a $15 \%$ do normal; b) encefalopatia atáxica: que se inicia, em geral, no segundo ano de vida, com episódios de ataxia durando, em média, uma semana e podendo ser deflagrados por "stresses" não específicos como infecções intercorrentes das vias aèreas superiores; susbseqüentemente podem desenvolver atrofia óptica e outros podem apresentar verdadeiras encefalopatias atáxicas; outros foram descritos como encefalopatia necrosante subaguda ou moléstia de Leigh 5 , havendo controvérsias a respeito de mutaçōes da CPH ocorrendo nas clássicas sindromes espinocerebelares como a ataxia de Friedreich. 2) Deficiência de piruvaio-carboxilase (PC): caracteriza-se pelos pacientes nascerem normais e no segundo semestre apresentarem crises convulsivas e deterioração progressiva, com retardo no desenvolvimento neuropsicomotor e controle pobre da cabeça, além de posturas bizarras. A atividade da PC era $1 \%$ do normal em fibroblastos, menor que $17 \%$ no fígado e menor que $0,1 \%$ no cérebro e córtex renal. $O$ diagnóstico das anormalidades do metabolismo do piruvato não é fácil, pois há uma variedade de estados clinicos em que aumenta o piruvato sangüineo, como na septicemia, choque, síndrome de Reye, deficiência de tiamina, como resultado de decréscimos adquiridos das enzimas CPH e CP; a distinção requer ensaios dessas enzimas em fibrob̉lastos cultivados, os quais ainda não estão estandardizados. Parece que as anormalidades do sistema nervoso nas alteraçôes do metabolismo do piruvato seriam causadas por deficiência na síntese de neurotransmissores, mais do que produção inadequada de ATP e compostos de alta energia. Na deficiência de $\mathrm{CPH}$ por exemplo, a oxidação deteriorada de piruvato leva ao decréscimo da geração de acetil-CoA, que, por sua vez, causa decréscimo na sintese de acetilcolina. Nas deficiências de PC há impedimento da produção de oxalacetato, que por sua vez, impede a glicogênese, levando a decréscimo da sintese de AMAC neurotransmissores como espartato, glutamato e GABA.

A encefalopatia necrosante subaguada (ESN, ou moléstia de Leigh) parece agora estar dentro dos EIM do piruvato tendo-se descrito em 4 pacientes deficiência de PC. Porém, recentemente, Eggers \& col.9 descreveram alterações mitocondriais em dois pacientes que foram à necrópsia, principalmente nos músculos cardiacos; concluem ser esta doença uma citopatia mitocondrial, podendo apresentar, miopatia, cardiopatia, nefropatia, e ENS; a disfunção mitocondrial explicaria a acidose metabólica permanente e a nefropatia (a qual não seria mera coincidência nas ENS); além disso, a degeneração esponjosa do cérebro (caracteristica da ENS) já foi descrita em outras anormalidades mitocondriais. Mais recentemente, Van Erven \& col.11 descreveram distúrbio do metabolismo oxidativo na moléstia de Leigh, praticamente demonstrando tratar-se de disfunçăo e/ou lesão mitocondrial.

Deficiência de beta-manosidase: descrita inicialmente em cabras como doença fatal, foi relatada por Wenger \& col.32 num menino de 46 meses de idade que se apresentava normal até 16 meses de idade, quando passou a ter regressão, principalmente na área da linguagem $e$, menos evidentemente, na área motora. Aos 46 meses apresentava caracteristicas faciais grosseiras, lembrando a MPS III (síndrome de Sanfilippo tipo A), alterações ósseas leves (idade óssea atrasada, pectus excavatum, cifose torácica leve), sem visceromegalias, retardo na fala e DM, hiperatividade e déficit de beta-manosidase em leucócitos, plasma e fibro- 
blastos cultivados; descobriu-se também que tinha déficit de enzima heparinasulfamidase (não-detectável) nos fibroblastos, semelhante à sindrome de Sanfilippo tipo A; porém, nesta síndrome a atividade da beta-manosidase é normal. Na urina, o paciente eliminava quantidade aumentada de MPS e a cromatografia em camada delgada mostrou tratar-se de heparan-sulfato, padrão semelhante à da sindrome de Sanfilippo. Os pais eram consangüíneos e tinham atividade reduzida da beta-manosidase à metade da normal, consistente com um padrăo autossômico recessivo de herança. Concluindo: todo paciente com retardo leve ou até severo do desenvolvimento mental e caracteristicas faciais grosseiras deve ser estudado quanto à atividade da beta-manosidase em leucócitos e/ou fibroblastos cultivados.

Outros EIM - Dentre outros EIM destaca-se a descrição recente 26 da deficiência de mioadenilato-deaminase (MAD), afecção relativamente bentgna, autossômica recessiva e que se caracteriza por fraqueza muscular iniciando-se na meninice ou no início da segunda década; até 1983, foram descritos 26 pacientes que apresentavam fatigabilidade fácil, câimbras ou mialgias após exercícios; as biópsias musculares não mostraram anormalidades ou somente leves anormalidades na distribuição das fibras; a atividade da MAD estava virtualmente ausente ( 0 a $6,2 \%$ da dos controles). Parece que a administraçăo de ribose auxilia na sintese de PP-ribose-P (fosforibosil-pirofosfato), que pode aumentar a sintese "de novo" de nucleotideos purínicos e, se se administrar junto alopurinol, para aumentar as purinas "salváveis" como a hipoxantina, poderia ser possível restaurar o pool de ATP mais rapidamente, seguindo-se a exercícios. Outra terapêutica são os exercícios condicionados, que parecem produzir músculos esqueléticos com maior proporção de fibras tipo II-2 e I. Nunca realizar exercícios extenuantes. A prova do lactato é normal, mas a produçāo de NH3 após exercício isquêmico do antebraço não ocorreu, o que pode servir de triagem.

Deficiência de fumarase: recentemente descrita como nova causa de encefalomiopatia mitocondrial por Zinn \& col.36 num menino que nasceu a termo, de mãe com 30 anos de idade (2 gestações e 1-para). Aparentemente normal ao nascimento, desde o primeiro dia passou a apresentar dificuldade em se alimentar, ganhar peso e letargia durante o primeiro mês; hipotonia intensa, retardo no desenvolvimento neuromotor e atrofia cerebral em torno do $6^{\circ}$ mês e morreu aos 8 meses de idade após otite média e provável septicemia. Não se realizou necrópsia. Os testes metabólicos de triagem reveleram niveis elevados moderados de lactato e piruvato, com aumento intermitente da relação lactato/ piruvato, porém sem acidose sistêmica. Havia padrão anormal de excreção urinária de ácidos orgânicos caracterizado por aumentos desproporcionados de fumarato, succinato e citrato. Por biópsias de fígado e músculo se pôde estudar o metabolismo mitocondrial e se mediu a atividade da fumarase, que estava virtualmente ausente, assim como a sua forma citosólica. Entretanto, diferentemente da evolução catastrófica deste caso, a acidúria fumárica já foi descrita em dois irmãos adultos com DM e retardo na fala (Whelan \& col., 1983, in Zinn \& col.36).

Recentemente, verificou-se a existência de um EIM - a deficiência de biotinidase 34 que resulta justamente da degradação de carboxilases endógenas por inabilidade em separar a biotina da bioticina ou de outros péptidos biotinilados e, portanto, em reciclar a vitamina biotina. Wolf \& col. 34 descreveram 4 pacientes de duas famílias, sendo dois descobertos num programa de seleção populacional por gota de sangue em papel de filtro e dois irmãos de um dos casos assim descobertos. Apresentavam os seguintes sinais e sintomas: crises convulsivas, "rash" na pele, alopécia, ataxia, hipoacusia, retardo no desenvolvimento e podendo chegar a coma e morte por descompensação metabólica, o que não aconteceu com seus casos: os dois descobertos por seleção populacional são pratłcamente normais e tinham apenas polifagia e leves alteraçôes cutâneas e cabelos esparsos quando definitivamente diagnosticados; os dois descobertos 
com mais idade (irmãos de um dos casos anteriores) apresentavam leve retardo só na fala, hipertonia e reflexos profundos vivos, sendo que a terapêutica ( $10 \mathrm{mg} / \mathrm{dia}$ de biotina) evitou que os dois primeiros tivessem problemas neurológicos e reverteu grande parte da sintomatologia dos dois últimos. Wolf \& col.34 fazem a hipótese de que a existência de biotina na dieta geral, embora em quantidade insuficiente, evitou que os mais velhos tivessem graves seqüelas.

\section{ASPECTOS DIAGNóstTICOS}

O diagnóstico dos EIM praticamente não oferece muitas novidades, pois vem sendo realizado há muitos anos em nosso meio, embora em nem todos os centros médicos e universitários. Iniciamos nosso interesse em diagnosticar EIM no inicio da década de 60 com simples testes seletivos urinários que podem ser efetuados em qualquer laboratório. No início da década de 70 , com a inauguração do Centro de Habilitaçāo da APAE, Schmidt \& col.22,24, passaram a realizar não somente estes simples testes urinários como também a dosagem de AMAC, segundo esquema desenvolvido naquele Centro que visa o estudo bioquímico de todo DM atendido ambulatorialmente 22. Entretanto, a maior preocupaçāo de nosso grupo não era o diagnóstico de casos já com seqüela, mas poder prevenir a DM. Para isso, a APAE apoiou a proposta de se iniciar testes de triagem populacionais, ao nivel de berçário, no intuito de, instalada terapêtica apropriada, poder-se evitar que o afetado bioquimicamente se tornasse um DM. Para tanto, foi proposta, em vista de sua maior frequiência, a pesquisa de Hiperfenilalaninemias, mediante coleta de sangue de RN segundo técnica proposta por Guthrie. Entretanto, em vez de se utilizar técnica bacteriológica com cepa especial de B. subtillis, achou-se mais conveniente e mais barato utilizar-se técnica espectrofluorométrica mediante autoanalisador, o que permite realizar cerca de 15000 dosagens de FAL/mês, com uma acurácia de $0,01 \mathrm{mg}$. O nivel plasmático normal de FAL é de 0,1 a $4,0 \mathrm{mg} \%$ e no RN, desde quie já alimentado por dieta láctea, iremos encontrar niveis acima de $4 \mathrm{mg} \%$. Os casos selecionados sāo redosados para confirmação e atualmente já se conta com cerca de 500000 dosagens, tendo se encontrado $30 \mathrm{FNC}$, o que dá uma freqüência aproximada de 1:16.000 nascidos vivos. Dizemos aproximadamente, pois, quase $1 / 3$ dos reconvocados para reconfirmar a hiperfenilalaninemia não retorna o que constitui fator de perda ou erro. Mais freqüente que as hiperfenilalaninemias é o Hipotireoidismo congênito (HC) para o qual foi proposto, utilizando a mesma gota de sangue colhida para FNC, dosar T4-Neonatal por técnica de micro-radio-imuno-ensaio (marcado com 125I). A freqüência de $\mathrm{HC}$, em geral, é de 1:3000 nascimentos e, em nosso meio, embora sendo um programa iniciado mais tarde que para a FNC, já realizamos 102221 dosagens, tendo se diagnosticado 28 casos de HC. Mediante esses dois programas, Schmidt \& col.23 conseguiram detectar, numa única paciente, os dois EIM ( $\mathrm{HC}+\mathrm{FNC})$, fato inédito na literatura mundial.

Outro modo de se diagnosticar precocemente $e$, de modo preventivo, um EIM é a determinação de heterozigotos, principalmente quando se dispóe de um marcador genético, como é o caso da moléstia de Tay-Sachs (TS). Schmidt \& col.24 mostraram a incidência de heterozigotos na cidade de $\mathrm{S}$. Paulo, dosando a hexosaminidase-A, a saber: 1/23,5 Judeus Ashkenazim e $1 / 56$ não-judeus, 0 que se constituiu numa surpresa, pois a frequêencia estimada em não-judeus, em geral, é de 1/300 pessoas. Em vista disso, através do Hospital Israelita Albert Einstein, foi iniciado programa de deteç̧ão de heterozigotos para hexosaminidase-A na comunidade em geral, programa esse que está em curso. Além disso, outros programas para detecção de EIM estão em ação, combinando o trabalho do Laboratório da APAE com grupos interessados em moléstias metabólicas hereditárias da Escola Paulista de Medicina e da Faculdade de Medicina da Universidade de São Paulo.

Evidentemente que tais técnicas não são novidade, pois testes de seleção populacional são realizados em países industrializados há mais de quase duas 
décadas. Também não é novidade que o diágnóstico efetivo de um EIM é aquele que pode ser realizado pela dosagem enzimatica, para se demonstrar o déficit. l'ais dosagens podem ser efetuadas em células periféricas (leucócitos) ou em biópsias de tecido e cultivos celulares dessas biópsias. Dispomos atualmente das dosagens celulares das seguintes enzimas: hexosaminidases $A$ e $B$, arilsulfatases A e B, beta-galactosidade, beta-glicosidase e esfingomielinase, permitindo não somente o diagnóstico de certezá de alguns EIM dos lípides, como também permitindo o diagnóstico pré-naıal e o subseqüente aconselhamento genético 3 . Este diagnóstico pode ser efetuado por amniocentese entre a 12 ? e $16^{\mathrm{a}}$ semanas de gestação, e realizado no liquido amniótico (LA), sendo preferível ser realizádo em células cultivadas do LA ${ }^{3}$. Esta tecnologia é segura, mormente tendo a ultrassonografia para localizar o nível de punçāo. Atuaimente, sem se necessitar de amrilocentese, realizam-se tais exames enzimáticos em células trofoblásticas cultivadas, que podem ser colhidas por via vaginal, ao nivel do trofoblasto, por aspiração ou por amniocentese. Esta tecnologia pode ser realizada entre a $\delta^{\text {a }}$ e $11^{\text {a }}$ semanas de gestaçāo 33 .

Pode-se detectar pré-natalmente os EIM por dosagens dos marcadores genéticos (isto é, enzimas e/ou proteinas). Porém, quando a enzima nāo se expressa nos amnióticos ou quando não há produtos metabólicos para se detectar no LA, o diagnóstico pré-natal pode se tornar difícil. Entretanto, nesses cacos, já se tentou, em alguns poucos casos, a biópsia do fígado fetal, para essas dosagens inzimáticas. Recentemente, para não ter que se recorrer a esse processo da biópsia intra-uterina (não isenta de perigos) descreveu-se nova tecnologia 12: a identificação de "polimorfísmos dos fragmentos de restriçāo da extensão" do locus gênico da ornitina-transcarbamilase humana, por meio da obtenção de vilosidades coriônicas para análise cromossômica, obtendo-se, então, amostras do DNA daquela enzima.

\section{ASPECTOS TERAFEUTICOS}

Para uma terapêutica de um EIM ser efetiva, é necessário que tal erro seja bem conhecido em seus três níveis de expressão: DNA, alteraçốes proteícas e da função celular. Tal conhecimento ainda não existe para qualquer condição genética, embora certas entidades, como as hemoglobinopatias, as talassemias e alguns tipos de deficiência da G-6-PD, tenham suas patogenias melhor conhecidas, porém não completamente. Na maioria delas, conhece-se, as vezes, extensamente um ou dois dos niveis, sempre faltando o conhecimento de outros. Por exemplo, na FNC se conhecem os vários derivados da FAL que podem alterar a formação da mielina cerebral, porém, não se sabe de que modo é executada esta ação. Portanto, a terapêutica dos EIM, na maioria dos casos ou não existe ou é sintomática, raramente sendo curativa, no sentido de evitar sintomatologia neuropsiquica, podendo-se dizer que na prática o defeito bioquímico quase sempre permanece; em alguns poucos casos (principalmente, vitamino-sensiveis) o defeito bioquímico pode ser reversível.

De modo geral, podemos entăo falar em tratamento curativo $e$ sintomático. $\mathrm{Na}$ dependência das entidades estudadas, estes tratamentos são variáveis 25: 1) por suplementar o agente desencadente que está em falta, como por exemplo, a tiroxina no hipotiroidismo e a hidrocortisona na síndrome adrenogenital; 2) suplementar o cofator faltante como por exemplo, a vitamina B-12 na acidemia metilmalônica, a vitamina B-6 na homocistinúria, a biopterina na ausência desse cofator em certas hiperfenilalaninemias; 3) limitação da ingestão do precursor através de dietas pobres ou seu agente nocivo, como por exemplo: limitaçăo da ingestão de FAL na FNC, de galactose na galactosemia, dos AMAC de cadeia ramificada (valina, leucina e isoleucina) na leucinose; 4) administração de um inibidor, como por exemplo, o alopurinol na hiperuricemia; 5) acoplamento de certas substâncias com outras nocivas, que se depositam nos tecidos, facilitando sua eliminação, como por exemplo, a penicilamina na cistinúria e na moléstia de Wilson; 6) limitação do uso de drogas potencialmente nocivas, 
dependendo da entidade em causa, como por exemplo, a limitação de quinino e antimaláricos na deficiência de G-6-PD, de succinilcolina na deficiência de pseudocolinesterase, de barbitúricos na porfiria; 7) utilização de indutores enzináticos como, o uso de fenobarbital nas hiperbilirrubinemias de reação indireta (Criggler-Najjar); 8) suplementação da falta enzimática ou proteica, administrando-se insulina no diabetes mellitus, gamaglobulina na agama ou hipogamaglobulinemia; 9) estabilização do déficit proteico com o emprego, por exemplo, de cianato ou mesmo uréia na anemia esferocítica; 10) construção de vias "fisiológicas" metabólicas, como realização do "shunt" porto-cava na glicogenose hepática; 11) ex-sangüineo-transfusão na tentativa de se retirar ou reduzir temporariamente substâncias nocivas da circulação sangüínea; 12) transplante de orgãos para suprir deficiências enzimáticas, tentado em alguns EIM, principalmente de rim, sem resultados convincentes; o transplante da medula óssea vem sendo tentado, assim como o de células pancreáticas (subcutaneamente); 13) leucoferese e plasmaferese periódicas, na tentativa de se fornecer a enzima deficitária, como nas mucopolissacaridoses. Introduzida em 1971, por Di Ferrante \& col., a plasmaferese não deu resultados, porque os niveis de alfa-1-iduronidase são muito baixos no plasma. Daí, a indicação da transfusão de leucócitos ou o transplante de fibroblastos. Estamos seguindo pacientes com MPS, baseados nas propostas de tratamento por leucoferese de Knudsen \& col. (1971), processando-se uma unidade a cada $2 \mathrm{e} 1 / 2$ a 3 meses, com melhores variáveis; 4 desses pacientes já estão sendo seguidos de 12 a 46 meses, sendo um com doença de Scheie, um com Hurler e 2 com Hurler-Scheie; após cada leucoferese há aumerito da excreção de MPS, a seguir uma queda; mensalmente é seguida a mucopolissacaridúria e quando os níveis urinários começam a se elevar, faz-se nova leucoferese. Sempre são feitos testes de linfotoxicidade comparando-se soro do paciente contra os leucócitos do doador, além de testar os antígenos HLA de ambos. Do ponto de vista neuropsicomotor a criança fica mais ativa, com fascies mais esperto, as articulações se tornam menos rígidas; as lesōes corneanas nâo se agravam e há regressão das visceromegalias. O tratamento da maioria das neurolipidoses ainda está nos seus primórdios, visando mais a uma terapêtica sintomática e/ou preventiva a nível de diagnóstico pré-natal (quando possivel) e aconselhamento genético. Em algumas doenças, tentou-se a substituição da enzima deficitária sem resultados satisfatórios, quer pela falta de pureza da enzima utilizada, quer pela dificuldade de se introduzir a enzima ao nivel do sistema nervoso para a sua devida utilização.

\section{RESUMO}

Apresenta-se análise dos avanços concernentes aos erros inatos do metabolismo (EIM) sob 4 aspectos: 1) da compreensão geral dos EIM, principalmente relacionados aos mecanismos, à localização gênica e à manifestação dos genes pela heterogenidade genética; 2) aos aspectos clínicos, apresentando de forma resumida a descrição ou de novas variantes dos EIM já conhecidos ou de novos EIM; 3) ao diagnóstico, em que se apresentam os meios diagnósticos de laboratório atualmente disponiveis em nosso meio: seja a dosagem de marcadores genéticos, sejam os testes de triagem populacionais a nivel de berçário, sejam deteç̧ōes de heterozigotos, assim como o diagnóstico pré-natal; 4) aos aspectos terapêtuticos, em que são apresentadas as variadas terapêtuticas substitutivas, ou dietas especiais, ou ainda as técnicas de plasmaferese e leucoferese, apresentando, quanto a esta última, alguns resultados observados em 4 mucopolissacaridoses.

\section{SUMMARY}

\section{Inborn errors of metabolism: recent advances.}

Four aspects of advances in inborn errors of metabolism (IEM) are analysed: 1) concerning the general comprehension of the pathogenesis, genic localization and genetic heterogeneity; 2) clinical aspects, with description of new 
variants of known IEM or new IEM; 3) laboratory diagnostic tests presently used in our country: dosage of some genetic markers (arylsulfatases, hexosaminidases, beta-glicosidase; beta-galactosidase and sphyngomyelinase), newborn populational screening (for hyperphenylalaninemia, and hypothyroidism), heterozygote detection (for Tay-Sachs disease) and also some prenatal diagnosis; 4) therapeutic aspects presenting substitutive treatment, special diets, plasma. pheresis and leucopheresis. The first results of 4 cases of mucopolysacharidosis treated with the last technic are presented.

\section{REFERENCIAS}

1. ARGOV, Z. \& NAVON, R. - Clinical and genetic variations in the syndrome of adult GM, gangliosidosis resulting from hexosaminidase A deficiency. Ann. Neurol. $16: 14,1984$.

2. BLASS, J.P. - Inborn errors of pyruvate metabolism. In ref. 27 ,pg. 193.

3. BOUÉ, J.; DELUCHAT, C.; NICOLAS, H.; OURY, J.F. \& DUMEZ, Y. - Diagnostic prénatal des maladies géniques sur villosités choriales. J. Génét. Human. 34:221, 1986.

4. BROWN, G.K.; HUNT, S.M.; SCHOLEM, R.; FOWLER, K.; GRIMES, A.; MERCER, J.F.B.; TRUSCOTT, R.M.; COTTON, R.G.H.; ROGERS, J.G. \& DANKS, D.M. Beta-hydroxyisobutyril coenzyme A deacylase deficiency: a defect in valine metabolısm assuciated with physical malformations. Pediatrics 70:532, 1982.

5. DE VIVO, D.C.; HAYMOND, M.W.; OBERT, K.A.; NELSON, J.S. \& PAGLIARA, A.S. - Defective activation of the pyruvate dehydrogenase complex in subacute necrotizing encephalomyelopathy (Leigh disease). Ann. Neurol. 6:483, 1979.

6. DIAMENT, A.J.: SCHMIDT, B.J. \& ROSEMBERG, S. - O diagnóstico neuropediátrico em deficiência mental. Anais Nestlé no 104, 1980.

7. DIAMENT, A.J. - O diagnóstíco pré-natal em Neurologia Infantil. In A.J. Diams $₫$ t (ed.): Neurologia Infantil. Ed. 2. 1986 (no prelo).

8. DURAN, M.: BEEMER, F.A.; TIBOSCH, A.S.; BRUINVIS, L.; KETTING, D. \& WADMAN, S.K. - Inherited 3-methylglutaconic aciduria in two brothers-another defect of leucine metabolism. J. Pediatr. 101:551, 1982.

9. EGGER, J.: PINCOTT, J.R.: WILSON, J. \& ERDOHAZI, M. - Cortical subacute necrotizing encephalomyelopathy: a study of two patients with mitochondrial dysfunction. Neuropediatrics 15:150, 1984.

10. ENDO, F.; KITANO, A.; UEHARA, I.; NAGATA, N.; MATSUDA, I.; SHINKA, T.; KUHARA, T. \& MATSUMOTO, I. - Four-hydroxyphenylpyruvic acid oxidase deficiency with normal fumarylacetoacetase: a new variant form of hereditary hypertyrosinemia. Pediatr. Res, 17:92, 1983.

11. van ERVEN, P.M.M.; RUITENBEEK, W.; GABRELLS, F.J.M. \& RENIER, WO. Disturbed oxidative metabolism in subacute necrotizing encephalomyelopathy (Leigh syndrome). Neuropediatrics $17: 28,1986$.

12. FOX, J.; HACK, A.M.; GOLBUS, M.S.; WINTER, S.; KALOUSEK, F.; ROZEN, R.; BRUSILOW, S.W. \& ROSENBERG, L.E. - Prenatal diagnosis of ornithine transcarbamylase deficiency with use of DNA polymorphisms. New Engl. J. Med. 315:1205. 1986.

13. GOLJAARD, H. - Genetic Metabolic Diseases. Early Diagnosis and Prenatal Analysjs. Elsevier/North-Holland, Amsterdam, 1980, pg. 3, 507.

14. GIBSON, K.M.; SWEETMAN, L.; NYHAN, W.L.; JAKOBS, C.; RATING, D.: SIEMES, H. \& HANEFELD, F. - Succinic semialdehyde dehydrogenase deficiency: an inborn error of gamma-aminobutyric acid metabolism. Clin. chin. Acta. 133:33, 1983.

15. JAEKEN, J.; CASAER, P. : COCK, P. de; CORBEEL, L. : EECKELS, R.; EGGERMONT, E.; SCHECHTER, P.J. \& BRUCCHER, J.M. - Gamma-aminobutyric acid transaminase deficiency: a newly recognized inborn error of neurotransmitter metabolism. Neuropediatrics $15: 165,1984$.

16. McKUSICK, V.A. - Mendelian Inheritance in Man. Catalogue of Autosomal Dominant, Autosomal Recessive, and X-Linked Phenotype. Ed. 6. Johns Hopkins Univ. Press, Baltimore, 1983, pg. xi. 
17. MEISTER, A, - 5-oxoprolinuria (pyroglutamic aciduria) and other disorders of gamma-glutamil cycle. In ref. 27, pg. 348.

18. MUDD, S.H. \& LEVY, H.L. $\sim$ Disorders of transsulfuration. In ref. 27.

19. PEIFFER, J.; HARZER, K.; SCHLOTE, W. - Diffuse-disseminated scleroşis combined with partial arylsulfate A(ASA) deficiency: mixed heterozygosity of ASA-and pseudo-ASA-deficiency. Neuropediatrics 15:59, 1984.

20. ROSENBERG, L.E. - Disorders of propinate and methylmalonate metabolism. In ref. 27, pg. 474 .

21. SCHINZEL, A. - Catalogue of Unbalanced Chromosome Aberrations in Man. Walter de Gruyter, Berlin, 1984, pg 1.

22. SCHMIDT, B.J. \& DIAMENT, A.J. - Erros inatos do metabolismo: diagnóstico e «Screening» populacional. Pediat. Prát. (Săo Paulo), edição comemorativa (1929-1979, pg. 20.

23. SCHMIDT, B.J.; SOLBERG, P.C.: DIAMENT, A.J. \& PIMENTEL, H, - Phenylketonuria in a patient with congenital hypothyroidism. Pediatr. Res, 2:176, 1981.

24. SCHMIDT, B.J.; DIAMENT, A.J.; KRYNSKI, S.; KAMEI, M.E.; RODRIGUES, M.M.C. \& TAKATA, S. - Neonatal mass screening of hereditary metabolic diseases in S. Paulo-Brazil. Acta paediatr. jpn. 24:75, 1982.

25. SCHMIDT, B.J. - Tratamento dos erros inatos do metabolismo. In A.J. Diament (ed.): Neurologia Infantil. Ed. 2. 1986 (no prelo).

26. SWAIN, J.L.; SABINA, R.L. \& HOLMES, E.W. - Myoadenilate deaminase deficiency. In ref. $27, \mathrm{pg}$. 1184.

27. STANBURY, J.B.; WYNGAARDEN, J.B.; FREDERICKSON, D.S.; GOLDSTEIN, J.L. \& BROWN, M.S. (eds.): The Metabolic Basis of Inherited Disease. Ed. 5. McGraw-Hill, New York, 1983.

28. STANBURY, J.B.; WYNGAARDEN, J.B.; FREDERICKSON, D.S.; GOLDSTEIN, J.L. \& BROWN, J.L. - Inborn errors of metabolism in the 1980s. In ref. 27, po. 3.

29. TANAKA, $\mathbf{K}$. \& ROSENBERG, L.E. $\rightarrow$ Disorders of branched chain amino acid and organic acid metabolism. In ref, $27, \mathrm{pg} .440$.

30. TOURIAN, A. \& SIDBURY, J.B. - Phenylketonuria and hyperphenylalaninemia. In ref. $27, \mathrm{pg} .270$.

31. VALLE, D. \& SIMELL, O. - The hyperornithinemias. In ref. 27, pg. 382.

32. WENGER, D.A.; SUJANSKY, E.; FENNESSEY, P.V. \& THOMPSON, J.N. Human beta-mannosidase deficiency. New Engl, J. Med. 315:1201, 1986.

33. WHO Working Group-Fetal diagnosis of hereditary diseases. Bull. Worid Health Organiz. 62:345, 1984.

34. WOLF, B.: HEARD, G.S.; JEFFERSON, L.G.; PROUD, V.K.; NANCE, W.E. \& WEISSBECKER, B.A. - Cinical findings in four children with biotinidase deficiency detected through a statewide neonatal screening program. New Engl. J. Med. 313: 16, 1985.

35. YOSHIDA, T.; TADA, K. \& ARAKAWA, T. - Vitamin $\mathbf{B}_{6}$ dependency of glutamic acid decarboxylase in the kidney from a patient with vitamin $B_{;}-$dependent convulsion. Tokotu J. exp. Med. 104:195, 1971.

36. ZINN, A.B.; KERR, D.S. \& HOPPEL, C.L. 一 Fumarase deficiency: a new case of mitochondrial encephalomyopathy. New Engl. J. Med. 315:169, 1986.

Clínica Neurológica, FMUSP - Caixa Postal 3461 - 01000 - São Paulo. SP - Brasil. 